\section{[in] J Oral Res}

\title{
Prosthetic dental management of a patient with anhidrotic ectodermal dysplasia. A case report.
}

\author{
Manejo protésico dental de un paciente con displasia \\ ectodérmica anhidrótica. Reporte de caso.
}

\section{Daniel Hernández-González.' Jennifer Orozco-Páez. ${ }^{2}$}

\section{Affiliations:}

'Oral rehabilitation department, faculty of dentistry, University of Cartagena. Cartagena, Colombia.

Dentistry program, faculty of health sciences, Corporación Universitaria Rafael Núñez. Cartagena, Colombia.

Corresponding author: Jennifer OrozcoPaez. Calle de la Soledad, Old City, No 5 -70, Rafael Núñez campus, dentistry program. Cartagena, Colombia. Phone: (57-5) 6439499. Email: jennifer.orozco@curnvirtual.edu.co

Receipt : 03/31/2020 Revised: 05/03/2021 Acceptance : 08/31/2021

Hernández-González D \& Orozco-Páez J. Prosthetic dental management of a patient with anhidrotic ectodermal dysplasia. A case report.

J Oral Res 2021; 10(4):1-6.

Doi:10.17126/joralres.2021.057
Abstract: Introduction: Ectodermal dysplasia (ED) comprises a broad group of genetic disorders characterized by alterations of the structures derived from the ectoderm, including those of the stomatognathic system. Case Report: The present article aims to report the prosthetic management of a patient with anhidrotic ectodermal dysplasia. A male patient diagnosed with ED who attended the dental consultation displaying oligodontia; underdeveloped alveolar ridges were observed. Results: The established treatment consisted of the adaptation of implant-supported fixed full-arch prosthesis designed through CAD-CAM technology for the lower jaw and of a removable partial prosthesis with muco-dental support for the upper jaw. The dental approach of patients with ED is based on a correct analysis of the facial characteristics and stomatological conditions of each subject. Conclusion: A multidisciplinary approach is mandatory due to the biological and functional complexity in biomechanical terms of these individuals.

Keywords: ectodermal dysplasia 1, anhidrotic; Christ-Siemens-Touraine; anodontia; dental prosthesis, implant-supported; dental implants; computeraided design.

Resumen: Introducción: La displasia ectodérmica (DE) comprende un amplio grupo de trastornos genéticos caracterizados por alteraciones de las estructuras derivadas del ectodermo, incluidas las del sistema estomatognático. Reporte de Caso: El presente artículo tiene como objetivo informar del manejo protésico de un paciente con displasia ectodérmica anhidrótica. Paciente varón diagnosticado de DE acudió a consulta odontológica por oligodoncia; Se observaron crestas alveolares subdesarrolladas. Resultados: El tratamiento establecido consistió en la adaptación de una prótesis de arcada completa fija implantosoportada diseñada mediante tecnología CAD-CAM para el maxilar inferior y de una prótesis parcial removible con soporte muco-dental para el maxilar superior. El abordaje odontológico de los pacientes con DE se basa en un correcto análisis de las características faciales y condiciones estomatológicas de cada sujeto. Conclusión: Un enfoque multidisciplinario es obligatorio debido a la complejidad biológica y funcional en términos biomecánicos de estos individuos.

Palabra Clave: displasia ectodérmica; Christ-Siemens-Touraine; anodoncia; prótesis dental de soporte implantado; implantes dentales; diseño asistido por computadora. 


\section{INTRODUCTION.}

Anhidrotic ectodermal dysplasia, also known as Christ-Siemens-Touraine syndrome, is a congenital disorder that affects ectoderm-derived structures, including those of the stomatognathic system. Intraorally, patients exhibit oligodontia, dental anomalies of size and shape (taurodontism and microdontia), hyposalivation, diastemas, and underdeveloped alveolar ridges, which causes a diminished lower facial third. ${ }^{1-3}$

This clinical condition makes oral rehabilitation a complex process, the most common prosthetic treatments in adults are implant-supported overdentures or fixed prostheses. ${ }^{4}$ Nevertheless, the treatment plan varies according to some factors such as age, sex, socioeconomic aspects, and education level; all of which are essential for planning the most appropriate dental management. In the case of young patients, Schnabl et al., ${ }^{5}$ and Golhman et al., ${ }^{6}$ reported the use of removable partial prostheses accompanied by or thopedic treatment, while Alnuaimi et al report the use of fixed prostheses in children as a new treatment modality, concluding that it adapts to the growth of the jaw, reduces the need to remake the prosthesis and has a better overall cosmetic result. ${ }^{7}$

However, the use of short implants in young people with severe oligodontia is also mentioned; among its benefits are the enhancement of craniofacial development (when used in specific areas of the jaw) and a reduced surgical approach, which favors rehabilitation and healing. ${ }^{8}$ Therefore, dental implants emerge as an appropriate treatment alternative for patients with ED.

The main objective of the dental treatment in individuals with ED should be to restore functionality and aesthetics, seeking to improve the quality of life of the patient. Taking into account the importance of this disorder, this work aims to report the prosthetic dental management of a patient diagnosed with anhidrotic ectodermal dysplasia.

\section{CASE REPORT}

A 19-year-old male patient attends a dental clinic with his guardian requesting treatment due to the absence of teeth in his mouth. As a relevant medical history, he mentioned the diagnosis of anhidrotic ec- todermal dysplasia. Both the patient and his mother denied a family history of the disease. The extraoral clinical examination revealed sparse and fragile lightcolored hair, as well as sparse eyebrows and eyelashes; a depressed nasal septum that gave the patient an older appearance; and protruding and everted lips with healthy semi mucosa.

The intraoral examination showed a healthy mucosa, without evident alterations; oligodontia and atrophy of the alveolar ridges. Clinically, only the deciduous upper right central incisor, the permanent upper left central incisor, and the upper right first molar were detected, the first two displaying a slightly conical shape and dental mobility (Figure 1A and B). Radiographically, generalized atrophy of both ridges and the presence of a root remnant in the lower jaw was observed (Figure 1C).

As a treatment for partial edentulism, an interdisciplinary dental management was carried out including oral surgery and oral rehabilitation specialists. The treatment plan consisted of designing a removable partial prosthesis with mucosa support for the upper jaw and a full-arch metal-free fixed prosthesis supported on short implants for the lower jaw. Before conducting the treatment, the procedures were explained to the patient and his tutor, both voluntarily authorized the execution of it by signing an informed consent form.

For the design of the prosthesis in the upper jaw, a final impression was taken with regular silicone, subsequently, an intermaxillary relationship test was performed, then the acrylic teeth were tried in wax, and the final prosthesis was finally adapted (Figure 3B).

In the lower jaw, six short implants (6mm length) were strategically placed in the lower jaw (Max 2.5, Bicon, Boston), distributed according to the dimensions of the edentulous ridge and the prosthetic needs for retention, stability, and support. Under local anesthesia with $2 \%$ lidocaine, a full-thickness mucoperiosteal flap was raised in the right and left area of the jaw, then, the implant bed was prepared according to the manufacturer's instructions, afterward, a continuous suture using polyglycolic acid was performed. Finally, a postoperative panoramic radiograph was taken (Figure $2 \mathrm{~A}$ and $2 \mathrm{~B}$ ). 
After 16 weeks of bone healing, the second surgical phase was conducted for the placement of temporary abutments (Figure 2C) and for impression taking with addition silicone (Elite HD +, Zhermack ${ }^{\circledR}$, Italy).
The impressions were sent to the laboratory for the elaboration of an implant-supported fixed denture. The prosthesis substructure was made with CAD/CAM technology using glass fiber-reinforced

Figure 1. Intraoral view.
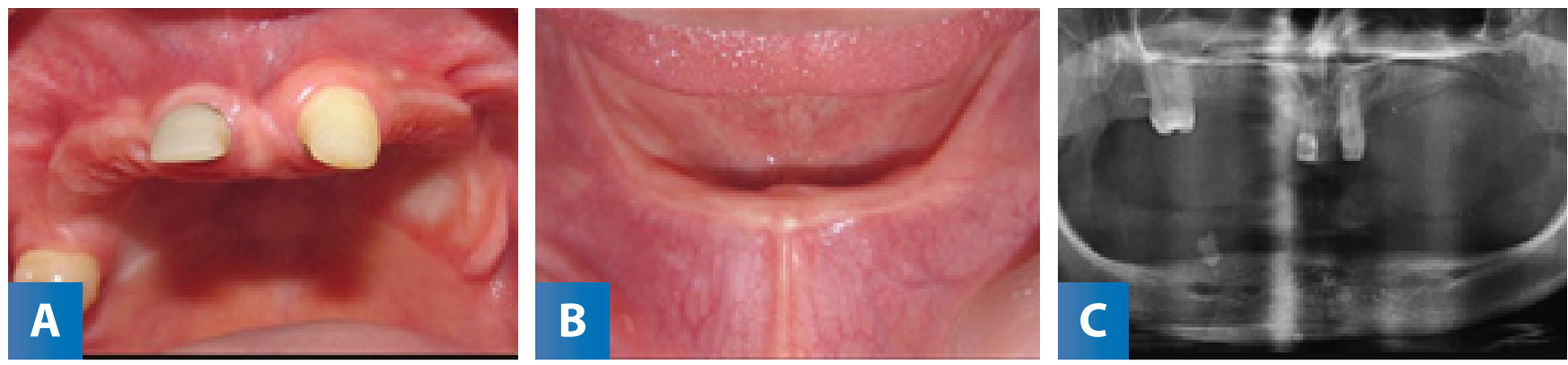

A: Oligodontia and atrophy of the alveolar processes can be observed in maxilla. B: Lower jaw. C: Initial panoramic radiograph.

Figure 2. Placement of the implants.
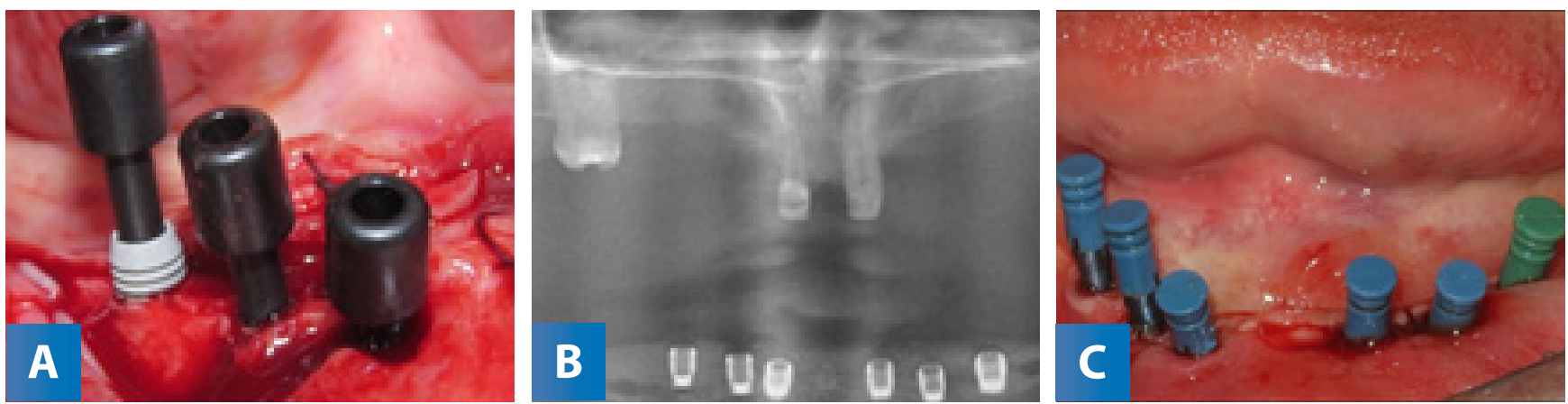

A: Placement of the implants in the lower jaw. B: Postoperative panoramic radiograph. C: Transfer Abutments placed in the mouth before the final impression taking.

Figure 3. Occlusal view of the lower.
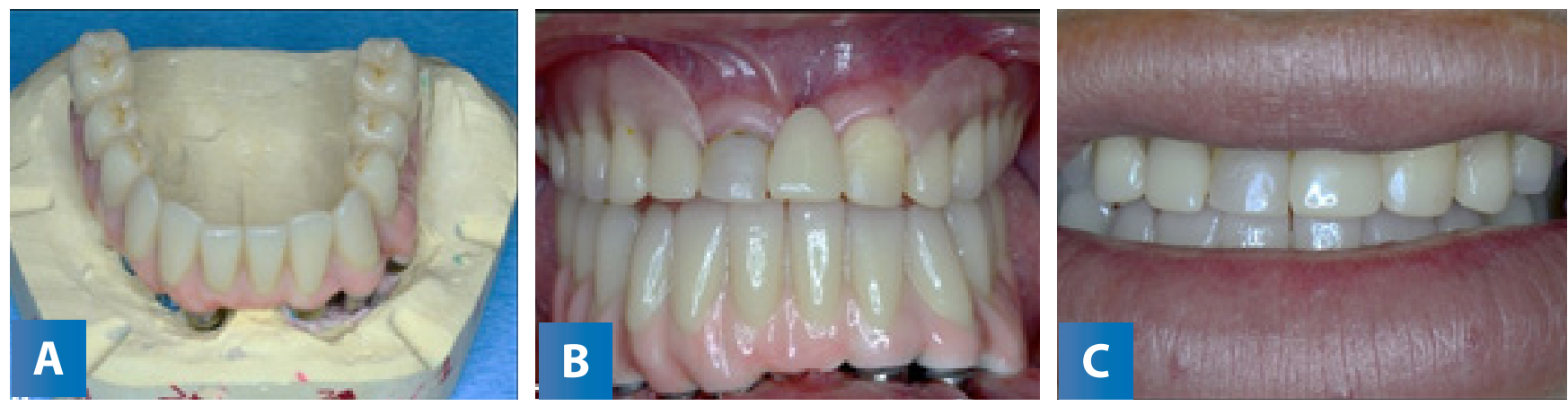

A: Occlusal view of the lower implant-supported fixed prosthesis. B: Removable partial prosthesis with muco-dental support in the upper jaw and fixed prosthesis in the lower jaw. C: View of the finished treatment. 
Figure 4. Control of implant-supported fixed prosthesis after 4 years.

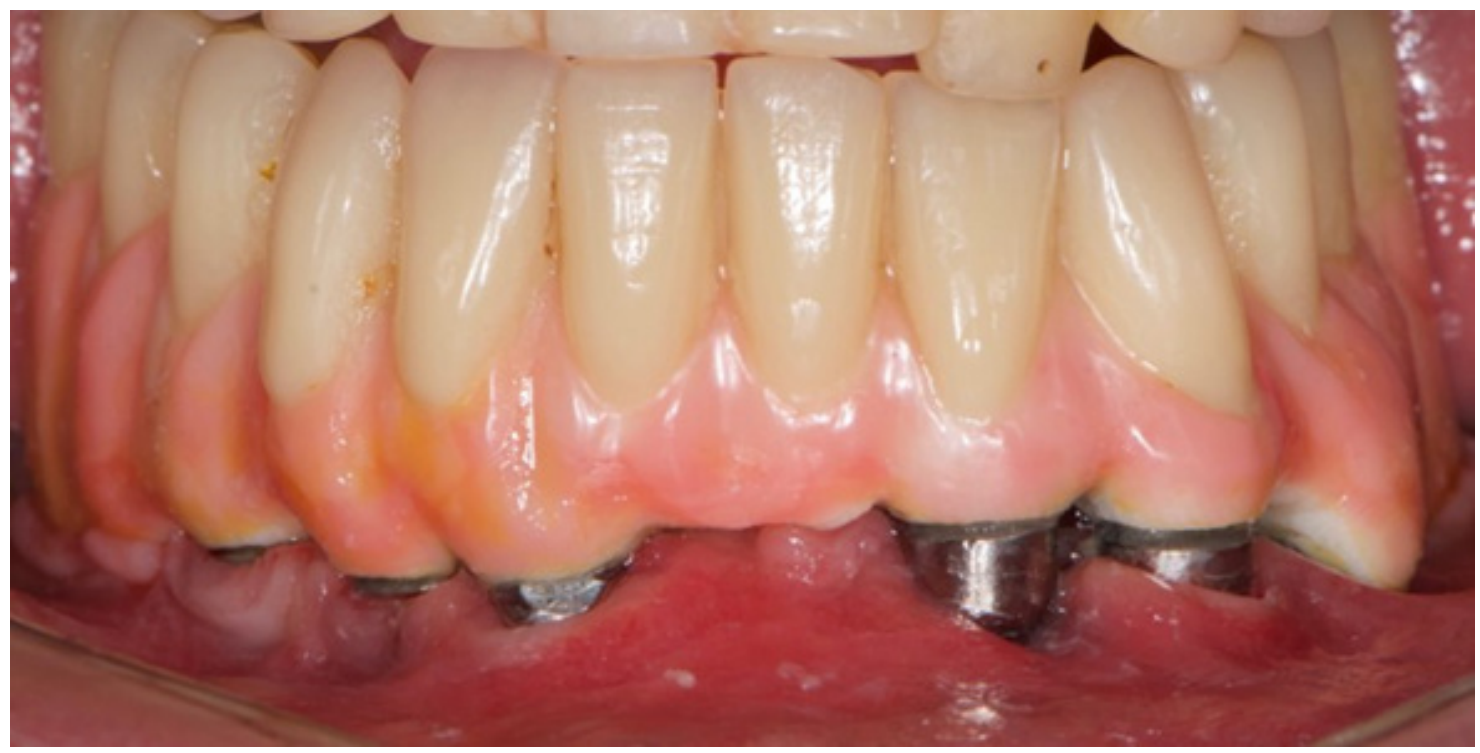

polymer (Trinia, Bicon, Boston), and the aesthetic covering was made with ceromer (Ceramage, Shofu, Japan) (Figure 3A).

Subsequently, the final cementation was performed. The patient expressed satisfaction with the final result of the treatment (Figure 3B and Figure 3C). The patient was followed for four years after treatment, the prosthesis was observed to be in good condition and correctly adapted (Figure 4).

\section{DISCUSSION.}

The oral rehabilitation of individuals with ectodermal dysplasia is essential as part of a comprehensive treatment that seeks to restore not only aesthetics but also speech and mastication functionalities, offering patients the opportunity to improve their quality of life. ${ }^{5}$ To achieve this objective, Bhargava et al., ${ }^{9}$ mentioned that the most appropriate approach should be carried out based on the age, the skeletal growth, development of the stomatognathic system, degree of malformation, dental agenesis and the motivation of each subject.

When it comes to young individuals, Mokhtari et al., ${ }^{10}$ mentioned that oral rehabilitation with removable partial prostheses and composite resin restorations is the treatment of choice as it will allow patients to have ideal nutrition, a normal appearance and a good speech function with significant psychosocial benefits.
In adolescents, orthodontic treatment could be an option to adjust teeth position and prepare the patient to receive fixed prostheses or implants in the future.

However, other conditions that are typical of the syndrome, such as poor development of the maxillary tuberosity and the alveolar ridges, make it difficult to obtain good stability and retention of removable prostheses, ${ }^{9}$ therefore, it is suggested that prostheses should be periodically adjusted and replaced when a decrease in vertical dimen-sion is detected since it is crucial to obtain an adequate distribution of the occlusal forces over the maxilla. ${ }^{11}$

Dental materials used to design full-arch fixed prostheses supported by implants are diverse and have become a target of study. ${ }^{12}$ They are classified into metalceramic, metal-acrylic, or metal-free systems. ${ }^{13}$ Regarding its use, literature shows a list of advantages and disadvantages for each of them without leaning towards a specific one, despite this, clinical criteria indicates the use of metal-ceramic or metal-acrylic systems due to their resistance and durability. ${ }^{14,15}$

However, metal-free systems offer good biomechanical behavior, stability, and fewer prosthetic complications. ${ }^{12}$ The metal bar restorations, computer-machined or cast, are widely used and can be coated with ceramic or acrylic depending on the prosthetic space requirements. ${ }^{14}$ Recent advances in polymers have yielded materials with improved 
mechanical properties for the oral cavity conditions. The advantages of this material lie in its low weight compared to chrome-cobalt ( $\mathrm{CoCr}$ ) or titanium ( $\mathrm{Ti}$ ), and in its elastic modulus that is similar to bone, which allows it to resist bending movements without breaking. ${ }^{15,16}$

Van Heumen et al., ${ }^{17}$ conducted a systematic review regarding fiber-reinforced polymer fixed partial prostheses, emphasizing the clinical studies that assessed the use of this material; the authors described that most cases had a survival rate $>92 \%$ after 5 years, and they concluded that the main complications of a fiber-reinforced polymer are delamination of the esthetic material, wear, and detachment; discoloration is regularly described as a problem while fracture of the structure is rarely mentioned.

As for this case, the specific conditions of the patient required a material with particular biomechanical characteristics, such as elasticity and stress absorption. Likewise, some aspects like the state of the alveolar ridges favored the indication of dental implants as part of the restorative treatment. To manage this patient, a fixed prosthesis was designed and confectioned whose substructure was made of glass fiber-reinforced polymer (Trinia, Bicon, Boston, MA, USA) in order to obtain the previously described qualities; acrylic teeth were used (Vita, Physiodens, Brea, CA, USA), and veneering was made with aesthetic material (Ceramage, Shofu, Japan).

The prosthesis was temporarily cemented (Tempbond, Kerr, Ger-many) and after the first 3 control appointments, it was cemented with a definitive luting material (Relyx U200, 3M, USA). Due to the use of glass fiber-reinforced polymer for the substructure, bone augmentation surgeries were avoided since the mechanical properties and elastic modulus of the material support distal extensions of up to 21 millimeters, so that a premolar and a molar can be substituted after the last abutment on implant.

\section{CONCLUSION.}

The dental management of patients with ectodermal dysplasia must be carried out in a multidisciplinary context due to the biological and functional complexity in biomechanical terms that these patients present. The use of short implants is a good treatment option, and its use should be considered according to the specific bone characteristics and oral conditions of each individual.

Conflict of interests: None declared by the authors. Ethics approval: Informed consent obtained from the patient and their tutor.

Funding: None.

Authors' contributions: All authors participated in the treatment and follow-up of the patient, as well as in the drafting and final approval of this manuscript.

Acknowledgements: To the Dental Implants Unit of the Faculty of Dentistry of the University of Cartagena for their support throughout the treatment. 


\section{REFERENCES.}

1. Reyes-Reali J, Mendoza-Ramos MI, Garrido-Guerrero E, Méndez-Catalá CF, Méndez-Cruz AR, Pozo-Molina G. Hypohidrotic ectodermal dysplasia: clinical and molecular review. Int J Dermatol [Internet]. 2018;57(8):965-72.

2. Gurcan AT, Seymen F, Yardimci S. Case series of ectodermal dysplasia and evaluation of oral findings: A literature review. Ann Med Res. 2020;27(1):420-5.

3. Bhakta P, Barthunia B, Nigam H, Pawar P. Ectodermal dysplasia - A rare case report. J Fam Med Prim Care [Internet]. 2019;8(9):3054-6.

4. Ghoveizi R, Siadat H, Nikzad S, Ommati Shabestari G, Soleimani Shayesteh Y. Full mouth rehabilitation of an ectodermal dysplasia patient with implant-supported prostheses: a clinical report. J Dent. 2013;10(3):283-8.

5. Schnabl D, Grunert I, Schmuth M, Kapferer-Seebacher I. Prosthetic rehabilitation of patients with hypohidrotic ectodermal dysplasia: A systematic review. J Oral Rehab. 2018;45(7):555-70.

6. Kassar WM. Dental Rehabilitation of a Child with Ectodermal Dysplasia: A Case Report. Int J Clin Pediatr Dent. 2019;12(4):362-5.

7. Alnuaimi R, Mansoor M. Prosthetic rehabilitation with fixed prosthesis of a 5-year-old child with Hypohidrotic Ectodermal Dysplasia and Oligodontia: A case report. J Med Case Rep. 2019;13(1):1-6.

8. Mello BZF, Silva TC, Rios D, Machado MAAM, Valarelli FP, Oliveira TM. Mini-implants: Alternative for oral rehabilitation of a child with ectodermal dysplasia. Braz Dent J [Internet]. 2015;26(1):75-8.

9. Bhargava A, Sharma A, Popli S, Bhargava R. Prosthodontic management of a child with ectodermal dysplasia: A case report. J Indian Prosthodont Soc. 2010;10(2):137-40.

10. Mokhtari S, Mokhtari S, Lotfi A. Christ-Siemens-Touraine Syndrome: A Case Report and Review of the Literature. Case Rep Dent. 2012;2012:1-3.
11. Hekmatfar S, Jafari K, Meshki R, Badakhsh S. Dental management of ectodermal dysplasia: two clinical case reports. J Dent Res Dent Clin Dent. 2012;6(3):108-12.

12. Bagegni A, Abou-Ayash S, Rücker G, Algarny A, Att W. The influence of prosthetic material on implant and prosthetic survival of implant-supported fixed complete dentures: a systematic review and meta-analysis. J Prosthod Res. 2019;63(3):251-65.

13. Zaparolli D, Peixoto RF, Pupim D, Macedo AP, Toniollo MB, Mattos M da GC de. Photoelastic analysis of mandibular full-arch implant-supported fixed dentures made with different bar materials and manufacturing techniques. Mater Sci Eng C. 2017;81:144-7.

14. Barootchi S, Askar H, Ravidà A, Gargallo-Albiol J, Travan S WH. Long-term Clinical Outcomes and Cost-Effectiveness of Full-Arch Implant-Supported Zirconia-Based and Metal-Acrylic Fixed Dental Prostheses: A Retrospective Analysis. Int J Oral Maxillofac Implants. 2020;35(2):395-405.

15. Cicconetti A, Passaretti A, Rastelli C, Rastelli, E, Falisi G. Innovations in oral and maxillofacial surgery: biomimetics meets physiology. J Biol Regul Homeost Agents. 2019;33(5):1609-13. 16. Sirandoni D, Leal E, Weber B, Noritomi PY, Fuentes R, Borie E. Effect of Different Framework Materials in ImplantSupported Fixed Mandibular Prostheses: A Finite Element Analysis. Int J Oral Maxillofac Implants. 2019;34(6):e107-14.

17. Van Heumen CCM, Kreulen CM, Creugers NHJ. Clinical studies of fiber-reinforced resin-bonded fixed partial dentures: A systematic review. European J Oral Scie. 2009;117(1):1-6. 